\title{
PRESENTACIÓN
}

\section{DOSSIER LITERATURA Y GUERRA}

La constelación en la cual entran los artículos que constituyen un dossier siempre tiene algo de sorprendente -y también algo de revelador-que no es, que no puede ser previsto por el comité de redacción que prepara la propuesta temática e invita a los autores a colaborar con ensayos y artículos. Por motivo del centenario del fin de la Primera Guerra Mundial en 1918 el asunto escogido para este número fue "Literatura y guerra". La conmemoración de esta fecha resulta relevante no solo para la historia de las naciones directamente involucradas en este conflicto, sino para todo el mundo moderno, considerando que el fin de la Primera Guerra prepara la historia del siglo XX: la derrota de la Rusia zarista frente a las tropas alemanas y austrohúngaras provoca la crisis política en Rusia y prepara la Revolución de Octubre y la creación de la Unión Soviética en 1917, mientras que en el mismo año los Estados Unidos intervendrán en la Guerra del lado de Inglaterra y Francia, y en 1918 los Catorce Puntos del presidente estadounidense Woodrow Wilson definirán las condiciones del armisticio entre los partidos bélicos. Con esto, empiezan a perfilarse las dos potencias, los dos sistemas políticos y económicos que determinarán la historia del siglo XX, no solamente en Europa: la Unión Soviética y los Estados Unidos.

Pero en esta Guerra la Modernidad llega también a un primer auge nefasto. Los movimientos de masas, las técnicas e inventos más sofisticados de la época, el avión, el teléfono, la cinematografía, todo se transformó de repente en un potencial medio de destrucción, preparando la catástrofe.

El mismo año del fin de la Guerra apareció el primer tomo de la Decadencia del Occidente de Oswald Spengler. A pesar de que el libro no fue escrito como reacción directa a la Primera Guerra -Spengler se había decidido por este título antes de su inicio, en 1914- y de que su autor no se refiere en él a la catástrofe humana y cultural asociada a esta, muchos, y especialmente los intelectuales latinoamericanos de los años 20, lo interpretaron como la confirmación del fin de la superioridad económica y cultural europea. El optimismo cultural de las vanguardias latinoamericanas es un reflejo de esta convicción. 
Las guerras siempre han sido eventos decisivos, tanto para los imperios, las naciones y los pueblos, así como también para las vidas de los individuos. En todas las literaturas y los distintos géneros que conforman el canon literario las guerras han sido un tema destacado. Atraviesan ya el Antiguo Testamento y la Ilíada, otro texto fundacional de la cultura occidental consagrado a la guerra, a la lucha entre griegos y troyanos. No hay ninguno de los textos fundacionales de las grandes literaturas nacionales europeas que no sea (también) la épica de una guerra. Y los textos latinoamericanos siguen a este ejemplo: las crónicas de la Conquista, la Araucana, A Confederação dos Tamoios, etc.... La observación de Michel Foucault en su "Genealogía del racismo", según la cual el discurso occidental interpreta las épocas de paz como prolongaciones de la guerra, como guerras con otros medios, y no -como quería Carl von Clausewitz- la guerra como continuación de la política, parece confirmarse si leemos estos textos de la literatura mundial.

Durante un largo tiempo la guerra fue considerada como flagelo inevitable de la humanidad, como voluntad y castigo de los dioses o como un medio legítimo de solución de conflictos. En la modernidad se produce un cambio decisivo a este respecto: las guerras ya no serán más consideradas como "naturales" o como castigos divinos, sino que tienen que ser justificadas. Aun más, la modernidad está convencida de que el progreso de la civilización humana debería hacer las guerras superfluas. Sin embargo, las guerras continúan. Encontramos ahora la argumentación absurda de que las guerras se hacen para evitar las guerras, que las armas se fabrican para asegurar la paz y no para la lucha. Las últimas décadas de nuestra historia están llenas de ejemplos de intervenciones bélicas para evitar una (presunta) guerra, en los que en muchos casos los políticos evitan de hablar de una "guerra" propiamente tal. La guerra ha perdido su prestigio. Esta ya no ofrece más un escenario donde se generen héroes, por lo menos no en las literaturas cultas, de élite, reconocidas por la crítica consagrada. La situación es bien diferente-lo sabemos- en las literaturas de masas y en el cine. Ahí la guerra no ha perdido su atractivo para el público. Por supuesto: las guerras de otros, ficcionales o imaginadas, ocurridas en un pasado remoto o en un futuro y espacio lejanos, guerras de las cuales se puede disfrutar con un cierto sentimiento de "thrill", desde la comodidad de una silla, sin tener que preocuparse por el propio bienestar.

Los artículos reunidos en este dossier tratan de guerras reales. En cuatro de ellos, los autores examinan textos literarios, incluyendo crónicas, en las cuales se tematizan conflictos bélicos en América Latina desde la Conquista. Todos estos conflictos, y esto no me parece que pueda considerarse como una 
simple coincidencia, aunque si lo fuera, resulta en todo caso muy significativa, son consecuencia del conflicto fundamental que atraviesa toda la historia de América Latina y que es resultado de la dependencia colonial de esta región: se origina con la Conquista, ámbito en el que se sitúa el artículo de Alejandro Viveros, "Indios conquistadores en la Descripción de la ciudad y provincia de Tlaxcala (1584) de Diego Muñoz Camargo", continúa con la Colonia, período en el que se instala el estudio de Luz Ángela Martínez, "Guerra y conciencia negativa en la construcción histórica del reino de Chile"-reaparece durante los movimientos de Independencia- que contextualizan la interpretación propuesta por Mónica González García del poemario Ismaelillo de José Martí en "Topologías de paternidad, patria y guerra en la primera poesía del exilio de José Martí", y es una de la causas importantes de la última guerra, la Guerra de las Malvinas, cuya representación en la literatura argentina es el asunto de la investigación de Luz Souto en su artículo "Malvinas, las islas prometidas. Aproximaciones a la literatura de la guerra".

Descubro aun otra preocupación común en estos cuatro estudios: explorar en qué medida aparece en estas manifestaciones literarias la subjetividad de los sujetos -valga la redundancia-involucrados en este conflicto. En su análisis de la guerra de la conquista en México, Alejandro Viveros busca develar que la actuación de los tlaxcaltecas al lado de las tropas españolas no debe ser interpretada solamente como consecuencia de un estatus de vasallaje, sino también como una decisión propia de participar como sujetos actores en una nueva organización política de esta región. Luz Ángela Martínez lee Cautiverio feliz de Francisco Nuñes de Pineda como un primer monumento de la subjetividad moderna en América Latina. También en la interpretación de las poesías de José Martí realizada por Mónica González García se hace evidente cómo el Martí poeta busca conciliar su deseo subjetivo, el amor por su hijo, con la necesidad política de su compromiso con la guerra de Independencia cubana. Y, finalmente, las narraciones sobre la guerra de la Malvinas estudiadas por Luz Souto son también testimonios de voces subjetivas y de su resistencia contra los discursos oficiales en su esfuerzo de silenciar este drama nacional.

Con la contribución de David Becerra, el dossier se aleja de la escena latinoamericana. En "La Guerra Civil en la novela española actual. Entre el consenso de la transición y el consenso neoliberal" nos acercamos a una forma de guerra que según varios historiadores es la más desastrosa: la guerra civil. Como en España, las guerras civiles fueron también el flagelo de varios países latinoamericanos en el siglo XX (Guatemala, Nicaragua, Colombia, 
Perú). En la modernidad estas guerras siempre involucran participaciones internacionales y son, como en la mayoría de los casos en América Latina al menos, el resultado de conflictos globales. Las novelas analizadas por David Becerra dejan en evidencia que la tardía recuperación de la memoria de la guerra civil en la literatura española se paga con el precio de la despolitización. En el contexto de nuestro dossier, sin embargo, el estudio de David Becerra recibe un papel adicional importante: su autor observa que la subjetivación no es una panacea contra la escritura convencional de la historia. Esta puede ser cooptada, puede cumplir una función despolitizadora y desviar -como es el caso de las novelas estudiadas por Becerra- nuestra atención de las causas históricas, políticas y sociales que provocaron, en este caso, de la guerra civil española.

En estos trabajos queda en evidencia la potencialidad de la literatura (incluyendo los textos de las crónicas) de contribuir, probablemente no a la reescritura de la historia, pero por lo menos a completarla o confrontarla con preguntas críticas, formuladas desde la subjetividad. Aun en el caso de las novelas españolas, esta subjetividad se revela como altamente problemática. Todos los textos que presentamos en este dossier se refieren a guerras concretas, a guerras históricas. Quedan completamente alejadas las escenificaciones de guerras imaginarias, ya sea del pasado o de un futuro utópico o distópico (como la Guerra de las galaxias), las narraciones en las cuales se juegue con una disposición antropológica del ser humano $-\mathrm{o}$, eventualmente, del sexo masculino-para la guerra. Tampoco se examinan textos literarios en los cuales se investiguen nuestras disposiciones psíquicas a participar en acciones de violencia contra "el otro", cuyas prácticas históricamente más complejas y destructivas son las guerras. Un dossier conformado por cinco trabajos solamente puede ofrecer una mirada restringida a las problemáticas que convoca, sin pretensiones de exhaustividad. No obstante, como observábamos al inicio, la constelación aleatoria que surge de la reunión de estos trabajos no carece de una lógica inherente, una lógica que nos parece significativa para el lugar y momento histórico de su publicación: la América Latina de inicios del siglo XXI.

Horst Nitschack

Director de la Revista Chilena de Literatura y coordinador del dossier Literatura y guerra 